\title{
The light of evolution
} Miranda Robertson

This month, Journal of Biology, like almost everyone else, has some specially commissioned articles to mark the $200^{\text {th }}$ anniversary of Darwin's birth, although it may not be immediately obvious where the Darwin articles end and our usual review content begins. This is in part a reflection of the admirable strength of our sister $B M C$ journals, from which the subject matter of our minireviews is largely drawn, in evolutionary biology and in genomics; but it is also in large part, of course, a tribute to the pervasiveness of what Paul Harvey [1] calls the Darwinian agenda.

Paul Harvey's is one of the two specially commissioned articles that is about Darwin himself rather than his legacy. We asked him to write on what Darwin actually proved, a question that arises from time to time in the context of the Popperian definition of the scientific process but that Harvey has adroitly sidestepped in favour of a selection of vivid examples of Darwin's singular character as a thinker and an experimental biologist.

Of course Darwin didn't get everything right. In some cases, given what was not known at the time, he couldn't have. An egregious case in which arguably he could have, but notably he didn't, was the Mendelian segregation of inherited characteristics. Harvey finds this failure surprising; Jonathan Howard, in the second of our two articles on Darwin [2], explains why Darwin failed, despite, in the course of extensive and meticulous breeding experiments with plants, having what we should recognize as Mendelian segregation patterns under his nose. I am not sure, especially after reading Howard's article, that it isn't more surprising that Mendel did see them, and realized, before the discovery of the chromosomal basis of inheritance at the beginning of the $20^{\text {th }}$ century, what they must mean.

The usual explanation for Mendel's success is his strong background in statistics and probability theory; Howard's explanation for Darwin's failure is that he was completely preoccupied with continuously varying traits, which were understood in Mendelian terms only with the mathematical analyses of the great population geneticists Fisher, Haldane and Sewall Wright, whose acrimonious relationship with Ernst Mayr - who did not believe in mathematics as a tool for investigating evolution provides the starting point for James Crow's [3] lively account of how profoundly important mathematical analysis has been in the study of evolution, from the construction of phylogenetic trees to the reconstruction of the migratory routes by which $H$. sapiens left his cradle in Africa to colonize the rest of the world - a recent contribution to which is discussed by Stanyon et al. in this issue [4].

We asked Paul Harvey and Jonathan Howard to write on Darwin; James Crow, Charles Stevens [5] and Laurence Hurst [6] were asked to write for our Darwin issue on evolutionary topics of special interest to them. Stevens, as a neurobiologist, is interested in how the neural circuitry of the brain is constructed so that its computational power is scaled to process input from sensory organs of sizes that vary across species and change during growth. He has chosen to revisit the principle of allometry, arguing that the power laws that describe the relationship of the relative sizes of parts of an organism to its absolute size are a consequence of the way that evolution works. Hurst, who is an evolutionary geneticist, asks how genomic tools and a modern understanding of molecular mechanisms can start to answer the question of how much of the genome is under selection - incidentally drawing attention to the limitations of the statistical tests that have been instrumental in the advances made by population geneticists in the study of evolution. One of their central achievements was to establish the role of socalled neutral mutations in evolution, now a linch pin of molecular horology and the kind of analysis described by Hurst, but fiercely contested by defenders of the Darwinian canon when first proposed (although Darwin himself was less doctrinaire, and willingly entertained the notion of selectively neutral variation - indeed Darwin's extraordinary open-mindedness is one of the notable features remarked by Paul Harvey [1]).

In our review this month, Robin Weiss [7] invites us on a breif trip into human prehistory with some original speculation on the unanswerable question of the evolutionary origin of human pubic hair, and draws some interesting parallels between the conjectured intraspecies promiscuity of human lice and the generally accepted 
intraspecies infidelities of microbial pathogens, and in particular the immunodeficiency viruses in which Weiss is an expert.

Our eclectic collection of Darwin articles and relevant minireviews does not begin to do justice to Darwin's vast, wide-reaching and absorbing legacy. We do not say anything (except in passing) about speciation, and only touch, quite briefly, in Crow [3] and less briefly - in Stevens [5] on what has become universally known as evodevo. On evo-devo there is a highly readable review by Shubin et al. in the Darwin issue of Nature [8]. On Darwin, and his failure to tackle speciation, there is more from Greg
Petsko in our sister journal Genome Biology [9].

But it would be nice to think that this bicentennial may provoke biologists in the hectic $21^{\text {st }}$ century to revisit the leisurely and measured writings of the man himself, which testify better than anyone can to his intellectual breadth, clarity and tenacity.

Miranda Robertson, Editor

editorial@jbiol.com

\section{References}

I. Harvey P:Q\&A: What did Charles Darwin prove? J Biol 2009, 8: I I.

2. Howard JC: Why didn't Darwin discover Mendel's laws? J Biol 2009, 8: 15.
3. Crow JF: Mayr, mathematics and the study of evolution / Bio/ 2009, 8: 13.

4. Stanyon R, Sazzini M, Luiselli D: Timing the first human migration into eastern Asia. / Biol 2009, 8:18

5. Stevens CF: Darwin and Huxley revisited: the origin of allometry. J Biol 2009, 8:14.

6. Hurst LD: Evolutionary genomics and the reach of selection J Biol 2009, 8: 12 .

7. Weiss RA: Apes, lice and prehistory. J Biol 2009, 8:20.

8. Shubin N, Tabin C, Carroll S: Deep homology and the origins of evolutionary novelty. Nature 2009, 457:8I8-823.

9. Petsko GA: Many happy returns Genome Biol 2009, 10:102.

Published: 27 February 2009

Journal of Biology 2009, 8: 10

(doi: 10.1 I86/jbiol /24)

The electronic version of this article is the complete one and can be found online at http://jbiol.com/content/8/2/10

(C) 2009 BioMed Central Ltd 